\title{
PERFEIÇÕES PURAS SEGUNDO ANSELMO DE AOSTA*
}

\author{
Manoel Vasconcellos \\ Universidade Federal de Pelotas
}

\begin{abstract}
The aim of this papper is to analyze «Pure perfections » (perfectiones simpiciter) according to Anselm. Pure perfections are those perfections that exclude any potency, that is, they do not admit any kind of imperfection. Pure perfections according to Anselm are always connected to the idea that, in every way, it is better to be than not to be, as it is shown in Monologion XV. We can say that God is the main subject of Anselm's reasonings, but this theme is covered by such particularity that it differs from any other topic which might raise philosophical interest. There is a fundamental ontological difference between God and all other beings and creatures. Only He exists by Himself, while creatures owe their existence to another being. This is a basic statement present in Anselm's philosophical talk of God.
\end{abstract}

Keywords: Anselm, pure perfections, God.

Resumo: O objetivo deste artigo é analisar "Perfeições Puras" (perfectiones simpliciter) em Anselmo. Perfeições puras são aquelas perfeições que excluem qualquer potência, isto é, elas não admitem nenhuma imperfeição. As perfeições puras, para Anselmo, estão também conectadas com a idéia de que, em qualquer caso, é melhor ser do que não ser, como aparece em Monológio XV. Podemos dizer que Deus é o principal tema da reflexão de Anselmo, mas este tema está envolto em uma tal particularidade que o diferencia de qualquer outra questão que pudesse suscitar interesse filosófico. Há uma diferença ontológica fundamental entre Deus e todos os demais seres criados. Somente Ele existe por si mesmo, enquanto as criaturas devem o seu ser a outro. Esta é uma constatação basilar na construção do discurso filosófico que Anselmo elabora em torno de Deus.

Palavras-chave: Anselmo, perfeições puras, Deus.

\footnotetext{
* Uma versão em língua inglesa do presente artigo, ligeiramente modificada, pode ser encontrada em Vasconcellos, M. "Pure Perfections to Anselmo f Canterbury", in: Pich, R. H. (edited by). New Essays on Metaphysics as Scientia Transcendens. Louvain-la-Neuv: Fédération Internationale des Instituts d'Études Médiévales, 2007, p. 233-248.
} 
Uma marcante característica do pensamento de Anselmo de Aosta é a sua manifesta fidelidade a Agostinho de Hipona. No entanto, tal fidelidade não consiste em um simples repetir de conteúdos. Ela está muito mais vinculada aos temas comuns e às verdades de fundo do que, propriamente, ao modo de apresentar os problemas. Pode-se dizer, contudo, que, em termos bem gerais, o grande tema da reflexão de Anselmo é o mesmo de Agostinho. No fim das contas, tanto o aostano, como o hiponense, quer conhecer Deus e a alma, nada mais ${ }^{1}$.

Tal como em Agostinho, também em Anselmo, Deus e o homem não são temas paralelos, pois sua abordagem sempre se mostra profundamente entrelaçada. Ao falar do homem, Anselmo nunca considera-o numa perspectiva puramente natural. Ora, isto significa que Anselmo jamais desvincula o homem da sua condição de criatura. Este homem que indaga sobre Deus, assim o faz por que sua alma "anela"2 por seu Criador. Também ao falar de Deus, o Doutor Magnífico deixa bem claro que não é possível conhece-lo em si mesmo. Um discurso racional, envolvendo a essência suprema, será sempre a tradução das considerações alcançadas por um esforço de racionalidade que, ao debruçar-se sobre o Absoluto, é capaz de conhece-lo até certo ponto (aliquatenus) ${ }^{3}$. Este conhecimento, necessariamente parcial, é a inevitável conseqüência da diferença ontológica radical que separa o criador da criatura, como veremos adiante.

Uma suscinta, mas bem característica elaboração do modo anselmiano de tratar a Deus, aparece logo no início do Proslogion, quando o autor apresenta três características divinas: Deus é aquele que existe verdadeiramente, que é o bem supremo, que não necessita de coisa alguma e que é a causa conservadora do ser de todas as criaturas, já que elas necessitam

\footnotetext{
${ }^{1}$ Cf. Agostinho. Solilóquios II, 2, 7.

2 "Domine deus meus, formator et reformatur meus, dic desideranti animae meae, quid aliud es, quam quod vidit, ut pure videat, quod desiderat" (Proslogion XIV, 111, 20 - 21). Ao longo do artigo, sempre que aparecerem citações das obras de Anselmo, procederemos da seguinte maneira: no corpo do texto, a citação em português e, em nota de rodapé, o texto em latim, conforme a edição crítica de F.S. Schimitt, publicada por Thomas Neslon et Filios, Edimburgo, 1946 e reproduzida em L'Oeuvre d'Anselme de Cantorbéry, Paris, Cerf, 1986ss, sob a direção de Michel Corbin. Quanto à tradução, seguiremos, no caso do Monológio e do Proslógio a edição publicada na Coleção Os Pensadores, vl. VII, São Paulo: Abril Cultural, 1973,por Ângelo Ricci.

${ }^{3}$ Cf. Proslogion XIV, 111, 21.
} 
dele para existirem e serem boas ${ }^{4}$. É evidente que todas estas noções são fundamentadas na fé, mas nunca é demais lembrar que, em Anselmo, fé e razão não se confundem, mas também não se excluem; é a fé que impulsiona a razão a encetar seu esforço dialético.

$\mathrm{Na}$ reflexão anselmiana Deus aparece como sendo portador de um existir "admiravelmente singular" e "singularmente maravilhoso", a tal ponto que, comparadas à sua existência, parece que as criaturas não existem ${ }^{5}$. A diferença reside no fato de que somente o supremo espírito existe de modo simples, perfeito e absoluto, fazendo que tudo o que não é ele tenha, por assim dizer, uma existência emprestada. Também é só o espírito supremo que possui uma eternidade imutável, enquanto qualquer criatura está marcada pela temporalidade e mutabilidade. Anselmo diz que tudo, menos Deus, passou do nada à existência. Tal passagem não foi autônoma, uma vez que as coisas diferentes do sumo espírito passaram para a existência não por si mesmas, mas por um outro ser, o que impede que a elas possa ser atribuída uma existência simples, perfeita e absoluta; acresça-se a isso o fato de que não são capazes de, por si mesmas, conservarem-se no ser. Todas estas razões permitem a Anselmo concluir, no capítulo XXVIII do Monologion que apenas o ser absoluto existe, sendo melhor atribuir a tudo o mais uma nãoexistência, ainda que não absoluta, porque as criaturas foram transformadas em algo, quando foram criadas do nada por aquele único que existe de maneira absoluta ${ }^{6}$.

Este preâmbulo é importante, pois queremos abordar o tema das perfeições puras na obra de Anselmo. Perfeições Puras (perfectiones simpliciter) são aquelas perfeições que excluem qualquer potência, isto é, não admitem nenhum tipo de imperfeição. O prof. Josef Seifert, aponta, com muita propriedade, em seu notável artigo " $A$ Vontade como Perfeição Pura e a Nova Concepção Não-Eudemonística do Amor Segundo Duns Scotus”, o papel relevante de Anselmo no que toca às perfeições puras, pois, mesmo que as perfeições puras possam ter raízes no pensamento antigo, elas teriam sido

\footnotetext{
4 "... quia deus vere est, et quia est summum bonum alio indigens, et quo omnia indigent ut sint et ut bene sint." (Proslogion, Prooemium, 93, 7-9).

5 "Videtur ergo consequi ex praecedentibus quod iste spiritus, qui sic suo quodam mirabiliter singulari et singulariter mirabili modo est, quadam ratione solus sit, alia vero quaecumque videntur esse, huic collata non sint". (Monologion, XXVIII, 45,25-46,1).

${ }^{6} \mathrm{Cf}$, Monologion XXVIII, 46, $24-31$.
} 
apreendidas por vez primeira com clareza filosófica por Anselmo, no Monologion?

Ora, as perfeições puras, tais como são concebidas por Anselmo, estão ligadas sempre à idéia de que em todos os sentidos é melhor ser do que não ser, como aparece no capítulo XV do Monologion. Antes, porém, de analisarmos este fundamental capítulo é preciso atentar para o que move o autor com esta obra. Ao anunciar, no início do Monologion, o tema fundamental daquele que foi seu primeiro tratado propriamente dito, o Prior da Abadia Beneditina de Lê Bec, na Normandia, anuncia, de uma certa maneira, o tema fundamental de todo o seu pensamento, qual seja, o tratamento da "essência divina e outras questões conexas" Deus é o tema por excelência da reflexão anselmiana, mas um tal tema está envolto em uma tal particularidade, que o diferencia de qualquer outra questão que pudesse suscitar interesse filosófico. Para Anselmo, de fato, como já acenamos, a razão que se dirige ao Absoluto é a razão de um homem criado. Há uma diferença ontológica fundamental entre Deus e tudo o mais. Apenas Ele é por si, enquanto as criaturas, devem o seu ser a outro, como já vimos. Esta é uma constatação basilar na construção do discurso filosófico que Anselmo de Aosta elabora em torno de Deus. Mesmo que reconheça as dificuldades, Anselmo não deixa de falar de Deus e ao faze-lo, faz uso de expressões bastante singulares, tais como algumas que aparecem no Proslogion: "não há nada maior que tu, nenhum lugar ou tempo te circunscreve"9; ou "tu, não estás, entretanto, em lugar e tempo nenhum; e tudo encontra-se em ti, pois nada pode abranger-te e, todavia, tu abranges todas as coisas" 10 .

Dada esta peculiaridade do objeto há de ter-se todo um cuidado para aborda-lo. Este cuidado está presente no Monologion, quando, por exemplo,

\footnotetext{
${ }^{7}$ As 'perfeições puras', cujo reconhecimento, ao menos implicitamente, ocupou um papel importante já na crítica do pré-socrático Xenófanes às concepções antropomórficas de Deus (ou dos deuses), características da religião grega, bem como na teologia filosófica de Platão e na teoria das idéias, perfeições essas que foram sempre pressupostas na metafísica e na teologia clássicas, foram apreendidas pela primeira vez, com plena clareza filosófica, por Anselmo de Cantuária, na sua obra Monologion". (Josef Seifert. "A Vontade como Perfeição Pura e a Nova Concepção Não-Eudemonística do Amor Segundo Duns Scotus", in Veritas, Porto Alegre, v. 50, n³, setembro 2005, p. 52).

${ }^{8} \mathrm{Cf}$. Monologion. Prologus, 7, $1-5$.

9 "Quoniam ergo maius te nihil est,nullus lócus aut tempus te cohibet..." (Prosl. XIII, 110, 13 - 14).

10 "... tu, autem, licit nihil sit sine te, non es tamem in loco aut tempore, sed omnia sunt in te. Nihil enim te continet, sed tu contines omnia". (Prosl. XIX, 115, $14-15)$.
} 
Anselmo se pergunta de que modo as qualidades freqüentemente atribuídas aos objetos, são convenientes para tratar da substância primeira. Esta preocupação é vista pelo autor como sendo de tal modo justa, que o faz sentir-se "fortemente impelido" a realizar tal intento, mesmo que entenda ser difícil encontrar, entre os nomes que servem para designar as coisas criadas do nada, alguns que possam ser adequadamente atribuíveis à substância criadora. Mesmo assim, entende que isto não deve ser negligenciado, razão pela qual busca ver "até que ponto" a razão pode avançar nesta investigação. É, precisamente este o tema de um capítulo do Monologion absolutamente fundamental para o tema das perfeições puras, o capítulo XV, em que o autor discorre sobre o que se pode dizer ou não, da substância primeira, substancialmente, isto é, o autor quer saber quais as determinações do ser que são atinentes à natureza suprema. Anselmo vai mostrar que as coisas relativas, justamente por não serem substanciais, não se aplicam à natureza suprema. Diz o autor:

No que diz respeito às coisas relativas, não há dúvida de que nenhuma delas é substancial ao ser a que se aplicam e, por isso, quando se afirma, da natureza suprema, alguma relação, esta não pode expressar-lhe a substância. Assim, pois, as afirmações de que ela é suprema, ou maior que todas as coisas criadas por ela, ou outras afirmações semelhantes a essas, em sentido relativo, está claro que não podem expressar a essência natural dela ${ }^{11}$.

Ora, o que isto significa? Significa que apenas os predicados absolutos podem ser adequadamente referidos à divindade. Assim sendo, mesmo que todas aquelas coisas em relação às quais a natureza suprema é definida como sendo "suprema" ou "maior", ou "perfeita", mesmo se essas coisas nunca tivessem existido, repito, mesmo assim, a natureza suprema não seria menos perfeita, ou seja, ela nada perderia de sua grandeza essencial, embora que não pudesse ser chamada de suprema ou maior. Por que isso? Simplesmente,

\footnotetext{
11 "Itaque de relatives quidem nuli dubium, quia nullum eorum substantiale est illi de quo relative dicitur. Quare si quid de summa natura dicitir relative, non est eius significativum substantiae. Unde hoc ipsum quod summa omnium sive maior omnibus quae ab illa facta sunt, seu aliud aliquid similiter relative dici potest: manifestum est quoniam non eius naturalem designat essentiam" (Mon. XV,28, 8-13).
} 
sustenta Anselmo, pelo fato de que tudo aquilo que ela é deriva de si mesma e não de algum outro ser. Assim sendo, deduz Anselmo:

... se é possível considerar a natureza suprema como não suprema sem, por isso, ela vir a ser maior ou menor de quando se considera como superior a todas as coisas, torna-se evidente que a palavra "suprema" simplesmente não expressa aquela essência que é completamente maior e melhor do que tudo aquilo que ela não é12.

Isto que foi racionalmente deduzido acerca do 'supremo' vale, igualmente, para qualquer outro relativo que, eventualmente, pudesse ser examinado, já que o relativo é incapaz de demonstrar a essência de qualquer coisa. Partindo daí o autor, ainda neste significativo capítulo décimo quinto do Monologion, aborda uma outra dificuldade para mostrar a diferença entre a essência criadora e as coisas criadas.

Observando os seres particulares, constata Anselmo que neles tudo aquilo que não faz parte dos relativos é de tal forma que, por vezes, é melhor ser aquilo que é e, por vezes, é melhor não ser aquilo que é. Mesmo considerando que uma coisa sempre vale mais do que sua negação (por exemplo, ser sábio é melhor do que não ser sábio), Anselmo salienta que, algumas vezes pode acontecer que seja melhor não ser do que ser. $\mathrm{O}$ autor elucida sua consideração com um exemplo: enquanto para o chumbo seria melhor ser de ouro do que não ser de ouro; para o homem, contudo, o melhor é não ser de ouro do que ser de ouro, já que o homem é melhor do que o ouro. Ora, a partir disso, pode Anselmo constatar que, no que diz respeito aos seres diferentes da natureza suprema, é melhor para eles ser do que não ser e, em certos casos, é melhor não ser do que ser. Mas, no que concerne à natureza suprema, sempre é melhor ser do que não ser. Anselmo está dizendo, na verdade, que há um sentido próprio e único de aplicação dos predicados à essência suprema. Não há nenhum caso a ela aplicável, onde o não ser possa, mesmo que eventualmente, superar o ser, pois ela é a única acima da qual nada maior pode haver. Ela, e só ela, é melhor do que todas as

\footnotetext{
12 "Si igitur summa natura sic potest intelligi non summa, ut tamem nequaquam sit maior aut minor quam cum intelligitur summa omnium: manifestum est quia, 'summum' non simpliciter significat illam essentiam quae omnimodo maior et melior est, quam quidquid non est quod ipsa". (Mon. XV, 28, 18 - 22).
} 
coisas que não sejam aquilo que ela mesma é. Resta que, ao referirmo-nos a uma tal natureza devemos atribuir de modo absoluto aqueles atributos abaixo dos quais está tudo o que ela não é. Conclui, então Anselmo, enumerando perfeições puras, que a natureza suprema "é viva, sábia, onipotente, verdadeira, justa, feliz, eterna e tudo aquilo que, igualmente, é melhor ser do que não ser, de maneira absoluta"13. Na perspectiva de Anselmo, como estamos vendo, as perfeições puras são absolutas e isentas de quaisquer limitações.

Sendo assim, Anselmo estabelece o que poderíamos chamar de um certo regramento, a fim de bem conduzir o pensamento humano a tratar da substância suprema. Ítalo Sciuto, comentando justamente este aspecto do pensamento anselmiano, vê aí a aplicação de uma tríplice regra: a regra da perfeição, da identidade e da unidade ${ }^{14}$. Conforme a norma da identidade ${ }^{15}$, tudo aquilo que se atribui à natureza suprema se constitui numa expressão do ser mesmo dessa natureza e não, apenas uma qualidade sua, de tal modo que é possível, acertadamente, referir que ela é a bondade suprema, a grandeza suprema, a justiça suprema etc, pois, de fato, ela é o ser supremo. Quanto à norma da unidade ${ }^{16}$, ela afirma que os predicados que são atribuídos à essência suprema, são idênticos entre si, não apenas pela identidade perfeita que existe entre eles, mas, também pelo fato de que cada um deles é a expressão da totalidade igual e una de todos os seus atributos. Por exemplo, em referência à natureza suprema, quando se fala de justiça ou de essência, na verdade, se está falando de uma mesma coisa e o mesmo se dá com cada uma das atribuições com as quais venha a ser designada.

Das três normas, é, sobretudo, a da perfeição que mais diz respeito ao que buscamos tratar aqui. De fato, segundo esta regra, o discurso sobre Deus deve, necessariamente, levar em conta que todos os predicados elencados

\footnotetext{
13 "Quare necesse est eam esse viventem, sapientem, potentem et omnipotentem, veram, iustam, beatam, aeternam, et quidquid similiter absolute melius est quam non ipsum" (Mon. XV, 29, 29 - 31).

${ }^{14}$ Cf. Italo Sciuto na "Introduzione" da edição italiana do Monologion, publicada por Rusconi Libri, Milnao, 1995.

15 "Quapropter cum quaeritur de illa quid est, non minus congrue respondetur:iusta, quam: iustitia" (Mon. $\mathrm{XVI}, 30,30-31)$.

16 "Quemadmodum itaque unum est quidquid essentialiter de summa substantia dictur, ita ipsa uno modo, una consideratione est quid quid est essentialiter". (Mon. XVII, 31, 25 - 27).
} 
sejam aqueles cuja afirmação é, de modo absoluto, melhor do que a negação ${ }^{17}$.

A mesma idéia está presente no Proslogion, quando Anselmo, logo depois de expor seu famoso argumento, declara que Deus é aquele que é "supremo entre todas as coisas", sendo o único que é existente por si mesmo. Acrescenta, em seguida, que a Deus, identificado como o "bem supremo" não pode faltar nenhum tipo de bem. Ele e só Ele é, pois, “justo, verdadeiro, feliz e tudo aquilo que é melhor que exista do que não exista"18.

Michel Corbin ${ }^{19}$ bem lembra que, em Anselmo, o fato de a essência suprema ser sua própria causa significa que ela esgota, em si, todas as possibilidades de ser, ou seja, ela está na posse de todos os bens concebíveis. Há, contudo, uma particularidade que vale à pena ser acenada no que diz respeito a esta posse de todas as perfeições por parte da essência suprema. É uma peculiaridade que fundamenta o próprio argumento da existência de Deus do Proslogion, em que o autor desenvolve a idéia de que Deus é "aquilo

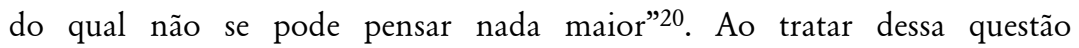
sobremaneira peculiar da argumentação anselmiana, vamos apresenta-la, seguindo de perto a análise efetuada por Aniceto Molinaro em seu estudo “'Unum argumentum': la peculiarità del pensiero di Dio"21. Para o estudioso de Anselmo, a impossibilidade de pensar algo maior é o mesmo que a impossibilidade de negar a existência de Deus, ou ainda, a impossibilidade de afirmar a sua não existência. Deus se impõe por si mesmo, como absoluta independência e subsistência, de tal forma a não depender de outro. Nesse sentido, Deus é único, já que, como origem absoluta, não admite ser comparado a nada que não seja Ele mesmo, afirmando-se, dessa forma, como a medida que não pode ser medida, e como Aquele que estabelece a medida de tudo. Por isso, Molinaro diz que não é lícito afirmar que Deus é, porque existe o mundo; é lícito, antes, dizer apenas que Ele é de modo original,

\footnotetext{
17 "sicut nefas est putare quod substantia supremae naturae sit aliquid, quo melius sit aliquomodo non ipsum, sic necesse est ut sit quidquid omnino melius est quam non ipsum". (Mon. XV, 29, 17-19).

${ }^{18} \mathrm{Cf} .$, Proslogion V

${ }^{19}$ Cf. Michel Corbin "Introduction" ao Monologion, in L'Oeuvre d'Anselme de Cantorbéry, Paris: Cerf, 1986ss, sob a direção de Michel Corbin., vl. I, p. 25.

20 Cf. Proslogion II

${ }^{21} \mathrm{Cf}$. Aniceto Molinaro. "'Unum argumentum': la peculiarità del pensiero di Dio", in: HOEGEN, Maternus (a cura di). L'Attualità Filosofica di Anselmo D'Aosta". Roma: Pontifício Ateneo S. Anselmo,1990. (Studia Anselmiana 101), p. $25-63$.
} 
absoluto e exclusivo, em virtude da impossibilidade de ser pensado como não ser, portanto, em força da necessidade da sua afirmação, a qual equivale à sua inegabilidade ${ }^{22}$.Com isso, fica demonstrado que "aquilo que não se pode pensar nada maior” não é uma conclusão a que se chegue, após um caminho percorrido, desde um ponto determinado de partida, ou seja, o argumento de Anselmo não é o ponto final de um processo em que partindo de dados preliminares, se chegasse até um ponto último, onde não fosse mais possível pensar algo maior.

Ora, ainda conforme Molinaro, aquele "algo de maior" que não pode ser pensado não diz respeito "a elementos que denotem toda uma gama de perfeições” que, se não existissem diminuiriam e que, em existindo, fazem aumentar "aquilo que não pode ser pensado maior". A impossibilidade de pensar "algo de maior" está concentrada na impossibilidade de pensar o nãoser. Do mesmo modo que "a possibilidade de pensar o não ser qualifica o finito; a impossibilidade de pensar o não ser qualifica o infinito, no sentido da infinita intensidade do ser, que exclui e vence todo não ser”. Não se trata de elevar ao infinito todas as perfeições. O que, aos olhos do comentador parece ser decisivo e determinante é o ato do pensamento, no qual a impossibilidade de não ser se manifesta como impossibilidade de pensar o não ser. Este ato do pensamento é a "aparição do ato de ser na forma da impensabilidade do não ser. Uma tal impossibilidade exprime a atualidade do ser e do pensamento”. É, a partir daí, que podem ser explicadas todas as perfeições: da necessidade de ser, formulada na impossibilidade do não ser, e de pensar o não ser, compete toda a riqueza das perfeições do ser afirmado na sua atualidade ${ }^{23}$.

É nesse preciso sentido, que deve ser entendido o já referido capítulo V do Proslogion, onde o monge beneditino afirma, como já vimos, que Deus é tudo aquilo que é melhor que exista, do que não exista, pois é o único existente por si mesmo, sendo "justo, verdadeiro, feliz e tudo aquilo que é melhor que exista do que não exista. De fato, é melhor ser justo do que não ser justo, ser feliz do que não ser feliz"24.

\footnotetext{
22 Op. cit., p. $46-7$.

23 Op. cit., p. 47-8.

24 "Tu es itaque iustus, verax, beatus, et quidquid melius est esse quam non esse. Melius namque est esse iustum quam non iustum, beatum quam non beatum". (Proslogion, V, 104, 15 - 17).
} 
Já pudemos vislumbrar como Deus e seu caráter absolutamente singular é uma questão de suma importância no pensamento anselmiano. Anselmo não nega que exista uma dificuldade fundamental para o homem falar de Deus, pois Ele é perfeito e o homem é imperfeito - afinal as marcas do pecado original não deixam de se fazer presentes -. Por outro lado, há uma exigência humana legítima em colocar-se diante de seu criador. Tal exigência se manifesta no desejo, diríamos, existencial, de dirigir-se ao Absoluto. Um tal desejo, evidentemente, vinculado à fé, converte-se, segundo Anselmo, naquele homem que está firme na fé, num esforço de dar as razões desse anseio. Assim, o desejo existencial assume as feições de um esforço filosófico, mesmo que os resultados que venham a ser obtidos pelo rigor dialético, não sejam mais do que parciais.

Ainda no Proslogion, Anselmo vai acrescentar que Deus é, igualmente, tão grande, que supera a própria capacidade humana de pensa$\mathrm{Lo}^{25}$. Isto está magistralmente expresso no breve capítulo XVI da obra. Vale a pena referi-lo integralmente:

É realmente inacessível a luz em que habitas, ó Senhor, e não há ninguém, exceto tu, que possa penetra-la bastante para contemplar-te com clareza. Eu não a vejo, sem dúvida, por causa do seu brilho, demasiado para os meus olhos,e, todavia, o que consigo ver, vejo-o através dela, da mesma maneira que o olho fraco do nosso corpo vê tudo aquilo que vê pela luz do sol, que, no entanto, não pode contemplar diretamente. A minha inteligência não consegue alcançar essa luz, porque difunde um esplendor demasiadamente vivo e que não tolera. O olho da minha alma não pode fitá-la por muito tempo, nem sustentar tão grande luminosidade: é, pois, ofuscado pela sua reverberação, vencido pela sua vastidão, turvado pela sua imensidade, confundido pela sua intensidade. Ó luz suprema e inacessível; ó verdade profunda e bem-aventurada, como estás distante de mim, embora eu esteja tão perto de ti! Quão afastada te encontras do meu olhar, quando eu estou continuamente presente ao teu! Tu estás presente, inteira, por toda a parte e eu não te vejo! Movo-me em ti, estou em ti e

25 "Ergo domine, non solum es quo maius cogitari nequit, sed es quiddam maius quam cogitari possit" (Proslogion XV, 112, $14-15$ ). 
não posso chegar até ti. Tu estás em mim, em torno de mim e eu não te $\operatorname{sinto}^{26}$.

Fica claro que a argumentação dialética de Anselmo no Proslogion está fundada na fé. Antes de ser filósofo, Anselmo é, evidentemente, um crente, mas, no seu pensamento, a fé não é impedimento para o trabalho da razão. Antes de ser obstáculo, ela é, precisamente um impulso, pois se trata da fé de um homem que foi criado por Deus e dotado de uma racionalidade que não assume uma postura dicotômica com sua origem divina. $\mathrm{Na}$ compreensão anselmiana, por um lado, a fé não teme a razão e, por outro, a razão não se basta a si mesma, ou seja, ela não prescinde da fé.

No caso do Proslogion, vemos que a razão, mesmo que fundamentada na fé, apresenta um nome de Deus. Este nome é "aquilo que não se pode pensar nada maior”. A origem deste nome, mostra Anselmo bem no início de sua argumentação, está na fé. De fato, diz ele: "Cremos, pois, com firmeza, que tu és um ser do qual não é possível pensar nada maior"27. Este nome divino, como salienta Yves Cattin ${ }^{28}$, não é um nome revelado, mas um nome que é afirmado como a expressão de um conteúdo da revelação, razão pela qual a fé não intervem na argumentação racional, a qual pode ter sentido mesmo para quem não possui esta fée ${ }^{29}$. É o trabalho da razão, mesmo que apoiado na fé, que vai mostrar a pertinência da existência divina, de tal modo que uma afirmação da não existência se torna infundada não porque foi afirmada por um insipiente, mas sim pela necessidade imposta pela razão. É

\footnotetext{
${ }^{26}$ Vere, domine, haec est lux inaccessibilis, in qua habitas. Vere enim non est aliud quod hanc penetret, ut ibi te pervideat. Vere ideo hanc non video, quia nimia mihi est; et tamen quidquid video, per illam video,sicut infirmus oculus quod videt per lucem solis videt, quam in ipso sole nequit aspicere. Non potest intellectus meus ad illam. Nimis fulget, non capit illam, nec suffert oculus animae meae diu intendere in illam. Reverberatur fulgore, vincitur amplitudine, obruitur immensitate, confunditur capacitate. O summa et inaccessibilis lux, o tota et beata veritas, quam longe es a me, qui tam prope tibi sum! Quam remota es a conspectu meo, qui sic praesens sum conspectui tuo! Ubique es tota praesens, et non te video. In te moveor et in te sum, et ad te non possum accedere.Intra me et circa me es, et non te sentio. (Proslogion XVI, 112,20 - 113, 4).

27 "Et quidem credimus te esse aliquid quo nihil maius cogitari possit" Proslogion II, 101, 4 - 5.

${ }^{28}$ Cf. Yves Cattin "S. Anselme et la tradition philosophique de l'immédiateté de Dieu", in: HOEGEN, Maternus (a cura di). L'Attualità Filosofica di Anselmo D'Aosta. Roma: Pontifício Ateneo S. Anselmo, 1990. (Studia Anselmiana 101), p. $125-126$.

29 Yves Cattin in Op. cit., p. 108, diz: ".. pour lui, la foi, pour être pleinement humaine et atteindre sa perfection, a besoin de se traduire dans les gestes humains, et principalement, elle doit être investie de raison".
} 
a pertinência racional que faz com que aquele que diz "Deus não existe" só possa ser um insipiente, ou seja, alguém que não tem razão ${ }^{30}$.

No Proslogion é evidente que Deus é nomeado a partir da fé, tanto que Anselmo, antes de anunciar o nome divino, utiliza, como vimos, o verbo crer. Apesar de estar fundamentado na fé, o nome divino é, como diz Cattin, uma reapropriação humana da palavra divina, a tal ponto que o "Tu" da fé se torna, numa perspectiva racional, um aquilo (aliquid) abstrato e indefinido. Sendo assim, a ratio anselmi não se restringe à fé, tornando-se acessível à experiência intelectual de todo homem, ao menos de todo homem que não seja um insipiente ${ }^{31}$.

Para Yves Cattin este nome divino, anunciado por Anselmo no início do Proslogion, refere-se a uma ordem de grandeza, ainda que esta não seja explicitada, pois o nome apenas diz que qualquer que seja a ordem de grandeza não é possível que se pense nada maior que ele. $\mathrm{O}$ nome divino deve, pois, ser entendido como sendo um "índice de transcendência"32. Procedendo desse modo, Anselmo indica Deus como um transcendente: ele não é aquilo que de maior se possa pensar, mas é algo que transcende a própria capacidade de pensar, ou seja, está além de todo pensamento, pois qualquer coisa que possa ser pensada está aquém da grandeza divina. O nome divino, expresso em categorias racionais fundadas na fé que é "aquilo que não se pode pensar nada maior"; trata-se do resultado de um esforço do pensamento que deseja expressar o objeto transcendente da sua fé. Cattin diz mesmo que este nome não visa uma representação de Deus. Se assim fosse, Anselmo estaria reduzindo a transcendência divina. O nome divino, que é um índice de transcendência, nomeia a Deus não no seu ser, mas na relação com o pensamento humano, onde Deus aparece como um limite que não pode ser ultrapassado.

Quando se fala do tema das perfeições puras em Anselmo não se pode deixar de lado uma questão que é importante: até que ponto a linguagem humana é capaz de bem expressar as perfeições divinas? É justamente, tratando deste tema que gostaríamos de ir encaminhando o encerramento da presente reflexão. $\mathrm{Na}$ obra anselmiana, de fato, os atributos que, usualmente,

\footnotetext{
30 Cf. Yves Cattin Op. cit., p.111.

${ }^{31} \mathrm{Cf}$. Yves Cattin Op. cit., pp $113 \mathrm{ss.}$

32 Idem.
} 
são usados para designar tudo o que não é Deus, possuem um sentido diverso quando são aplicados à essência suprema. Por exemplo: posso afirmar que Pedro é grande e, igualmente, posso falar que Deus é grande. No entanto, a grandeza da criatura Pedro não pode ser comparada com a grandeza daquele que não apenas é o criador de Pedro, mas de todas as demais criaturas. A designação da grandeza de um e Outro, além disso, é afirmada pela mesma linguagem humana, a linguagem de um ser criado. Está posto um problema que é relevante: o discurso da criatura racional é capaz de expressar, adequadamente, os atributos divinos?

Coloman Viola, abordando este aspecto do pensamento anselmiano em seu estudo "Saint Anselm, The Theologian of the Greatness of God"33 nota como as categorias aristotélicas, conhecidas e utilizadas por Anselmo, não são de todo apropriadas para a designação das perfeições divinas, pois, grandeza, para continuarmos com o mesmo atributo, é algo que se atribui a coisas que podem ser, de alguma forma, medidas. No entanto, como mensurar a grandeza divina? Afinal de contas, a própria Escritura afirma: "Nosso Senhor é grande e onipotente e sua inteligência é incalculável”34. Tomada a grandeza, apenas numa perspectiva quantitativa, teríamos de concluir que Deus não é grande, uma vez que a grandeza não poderia, ao menos de modo pleno, ser a Ele aplicada.

Anselmo, contudo, ao falar da grandeza divina assume uma perspectiva um tanto diferente, precisamente aquela que também Agostinho assumiu no seu tratado sobre a Trindade ${ }^{35}$, quando diz que Deus é grande, não por participar da grandeza, mas por ser uma grandeza essencial, ou seja, Ele é a grandeza pela qual é grande tudo aquilo que recebe este atributo. $\mathrm{O}$ mesmo vale para qualquer predicado atribuível à divindade. Há, porém, uma particularidade no modo anselmiano de analisar as perfeições divinas. Tratase da relação que elas comportam com a idéia de elevação. Deus, de fato, é referido, no Monologion, como sendo summum, Summa essentia etc. Notese que importantes estudiosos de Anselmo como Richard Southern ${ }^{36}$ e

\footnotetext{
${ }^{33} \mathrm{Cf}$. Coloman Viola. "Saint Anselm, The Theologian of the Greatness of God". In: Hermathena - A Trinity College Dublin Review nº 166, Summer 1999, p. 93 - 122.

${ }^{34}$ SI 147 (146 - 147), 5.

35 Cf. Agostinho. De Trinitate V, 10, 11.

${ }^{36} \mathrm{Cf}$. Richard Southern. Saint Anselm and his Biographer. London/N.York: Cambridge University Press, 1963.
} 
Coloman Viola ${ }^{37}$ relacionam esta construção conceitual com o fato contado pelo biógrafo de Anselmo Eadmero ${ }^{38}$, segundo o qual o menino de Aosta, no norte da Itália, tendo crescido em meio aos Alpes, desde sua tenra infância, impressionava-se de tal forma com as altas montanhas, a ponto de imaginar que no mais elevado delas, ou seja, em seu sumo, estaria Deus. Mais tarde, o intelectual Anselmo identificará Deus como sendo o mais elevado, o sumo ser, superior a tudo o que existe. A perfeição está, pois, ligada à sumidade, no sentido de uma máxima elevação.

Coloman Viola identifica neste modo de proceder do Doutor Magnífico o que chama de um princípio da "dialética da grandeza", princípio este que nada mais seria do que a busca de uma clarificação, a partir de uma constante comparação entre os diferentes modos de ser, visando chegar até um sumo, até um grau de tal modo elevado que não admita algo maior. Quando se logra atingir este algo (aliquid), atingiu-se aquele máximo que a mente humana poderia pensar. Esse processo dialético comportaria dois momentos: um primeiro, onde Anselmo atinge uma grandeza que é como o ponto máximo atingível pela capacidade humana de pensar. Neste primeiro momento, acaba-se por eliminar todas as coisas criadas, pois elas comportam sempre uma inerente limitação, a fim de se chegar a algo que está acima dos limites espaço-temporais, algo este que, por assim dizer, preenche totalmente a capacidade do pensamento humano. Não se trata aqui, aponta bem Viola, de uma pura e simples adição de quantidades, mas há, sim, uma adição de qualidade. A idéia do Proslogion de que Deus é aquilo que não se pode pensar nada maior comportaria, pois, um plus qualitativo e não quantitativo.

Há, porém, um segundo momento neste processo dialético da grandeza divina. Se antes se pôde chegar ao máximo da capacidade humana de pensar, agora se vai além. Trata-se do reconhecimento de que a divindade é mais do que isso, pois, como é dito no capítulo XV do Proslogion, trata-se de algo de tal modo perfeito, que transcende a própria capacidade humana de pensa-lo. De fato, diz Anselmo: "Portanto, ó Senhor, tu não és apenas

37 Cf. Coloman Viola. "Saint Anselm, The Theologian of the Greatness of God". In: Hermathena - A Trinity College Dublin Review no 166, Summer 1999, p. 93 - 122.

38 Eadmero. "Vie de Saint Anselme". In: L'oeuvre de Saint Anselme de Cantorbery sous la direction de Michel Corbin - vI. IX, textos da edição de F. S. Schimitt com introdução, tradução e notas por M. Corbin e outros. Paris: Cerf, 1994. 
aquilo de que não é possível pensar nada maior, mas és, também, tão grande que superas a nossa possibilidade de pensar-te" ${ }^{39}$. Este segundo momento é um reconhecimento explícito de que a limitada criatura racional não é capaz abarcar a perfeição divina.

Reporto, aqui, uma concepção que julgo bastante oportuna, quando se trata da questão das perfeições puras e sua aplicação a Deus no pensamento de Anselmo. Trata-se do papel absolutamente central que ocupa a idéia de grandeza na reflexão anselmiana. Esta centralidade é muito bem apontada por Coloman Viola nos seus escritos, particularmente no que citamos anteriormente, ou seja, seu artigo "Saint Anselm, The Theologian of the Greatness of God”. Para este estudioso, a grandeza divina é uma categoria diferenciada no modo anselmiano de ocupar-se com Deus, pois, se é certo que se pode dizer com justeza que Deus é amor, que é bondade, que é verdade, que é misericórdia etc, que diferença teria, então, para o homem, dizer que Deus é grande? O diferencial é que apenas a grandeza torna possível ao homem pensar a existência de Deus e todos os seus demais atributos no mais elevado grau. Na verdade, a grandeza não seria um atributo como qualquer outro, só ela é capaz de englobar a natureza divina e seu modo de existir. Segundo Viola, podemos dizer, por exemplo, que Deus é amor, mas não é possível saber se Deus é amor no mais alto grau ou apenas no passado, ou presente, ou futuro, ou se Ele é amor apenas aqui, para as pessoas que estão vivendo em nosso limitado espaço. A grandeza teria a capacidade de "explodir todos os limites", permitindo que o homem possa pensar a existência, a natureza e os atributos divinos de modo ilimitado. Dessa forma, a grandeza divina aparece como sendo o modo privilegiado, no qual Deus pode ser concebido por nós de modo plenamente verdadeiro.

Há uma consideração, contudo, que nos parece importante seja feita ao chegarmos a este ponto de nossa reflexão: a grandeza, entendida como sendo por assim dizer uma síntese de todas as perfeições divinas não implicaria, necessariamente, na impossibilidade de que se possa dizer qualquer coisa que seja a respeito da divindade? Ou seja, sendo Deus de tal modo grande, de tal modo perfeito que não apenas é "aquilo que não se pode pensar nada maior”, mas, além disso, supera a própria capacidade de pensa-

\footnotetext{
39 "Ergo domine, non solum es quo maius cogitari nequit, sed es quiddam maius quam cogitari possit" (Proslogion XV, 112, $14-15$ ).
} 
Lo, uma tal constatação não comportaria, igualmente, a constatação de que Ele não poderia ser objeto de discurso racional? De fato, o sumamente perfeito evidencia que tudo o que não é ele - e este é precisamente o caso da criatura racional - possui imperfeições que, por serem tais, não apenas apontam para uma diferença ontológica com o ser do criador,mas mostram também a imperfeição inerente ao discurso racional para tratar do sumamente perfeito. Anselmo trata desta questão no final do Monologion. No capítulo LXV, por exemplo, ele reafirma que a essência suprema está de tal modo acima de tudo o mais que, embora sejam utilizadas para tratar dela as mesmas palavras costumeiras para tratar de outros objetos o significado é diverso. Diante disso o autor se pergunta: "se o significado usual das palavras é-lhe estranho, tudo aquilo que a razão nos permitiu discutir sobre ela não lhe diz respeito. Mas, então, como poderíamos ter encontrado algo de verdadeiro acerca da essência suprema, se aquilo que averiguamos é tão diferente dela?"40

O problema posto não é pequeno, pois o que está em jogo é a própria validade de todas as conclusões que a razão pode chegar acerca da essência e da existência divinas. A solução proposta por Anselmo concilia a grandeza divina e a pertinência dos resultados obtidos pelo discurso racional. Anselmo diz não ser possível conhecer diretamente a Deus, mas isto não implica na impossibilidade de um seguro conhecimento indireto. Mesmo diante da inefabilidade divina os resultados obtidos não podem ser desprezados. Mesmo que os nomes com os quais usualmente expressamos a natureza suprema não sejam capazes de dizer, de modo absoluto e completo, aquilo que ela é, eles são suficientes para expressar uma adequada semelhança. Do mesmo modo que a imagem de uma coisa vista num espelho não é a coisa em si, nem por isso deixa de ser uma adequada expressão dela, ainda que indireta. Assim é a natureza divina e suas perfeições em relação a nossa capacidade de pensa-la e expressa-la racionalmente.

Estas considerações evidenciam algo absolutamente relevante $\mathrm{e}$ também um aspecto sobremaneira interessante do pensamento de Anselmo, algo que é marcante diante do seu contexto filosófico mais imediato, mas que

\footnotetext{
40 "Si ergo usitatus sensus verborum alienus est ab illa: quidquid ratiocinatus sum non pertinet ad illam. Quomodo igitur verum est inventum esse aliquid de summa essentia, si quod est inventum longe diversum est ab illa?" (Monologion LXV, 76, 6-9).
} 
transcende esse mesmo contexto. Anselmo, por um lado, apresenta uma resposta pertinente, mostrando, de certa forma, ao século XI que assistiu às desavenças de Lanfranco e Berengário, à desconfiança de Pedro Damião, à impetuosidade de Roscelino, Anselmo mostra a todos que é possível construir um discurso racional acerca de Deus, sem ferir a fé. Não é preciso temer a razão, nem desconfiar demasiadamente de seus resultados. $\mathrm{O}$ que importa é saber usa-la. Há, porém, algo mais em Anselmo, algo que julgamos importante e que faz dele, inegavelmente, um grande filósofo que vai além do seu momento histórico. Anselmo, de fato, com a construção conceitual que leva a cabo, permite ao homem que legitimamente indague sobre o que o transcende. Dessa forma, Anselmo, para usar a feliz expressão do Prof. Josef Seifert, contribui de modo decisivo para a metafísica clássica e a filosofia da religião ${ }^{41}$. É claro que a fé também possibilita que se trilhe um tal caminho, mas Anselmo mostra, sem negar a fé que possui, que aquele desejo próprio e profundo do homem de dirigir-se ao que lhe ultrapassa, um tal desejo não está condenado ao silêncio da palavra, mesmo que esta não seja capaz de exprimi-lo na sua totalidade.

${ }^{41}$ Cf. Veritas, Porto Alegre, v. 50, n³, setembro 2005, p. 54. 